\title{
Adaptive PD-SMC for Nonlinear Robotic Manipulator Tracking Control
}

\author{
Tolgay KARA ${ }^{1}$, Ali Hussien MARY ${ }^{2}$ \\ ${ }^{1}$ University of Gaziantep, \\ Department of Electrical and Electronics Engineering, \\ Gaziantep, 27310, TURKEY. \\ kara@gantep.edu.tr \\ ${ }^{2}$ University of Baghdad, \\ Al-Khwarizmi College of Engineering, \\ Baghdad, IRAQ. \\ Ali.kinani@gantep.edu.tr
}

\begin{abstract}
This paper presents an adaptive and robust control scheme, which is based on Sliding Mode Control (SMC) accompanied by Proportional Derivative (PD) control terms for trajectory tracking of nonlinear robotic manipulators in the presence of system uncertainties and external disturbances. Two important features make the proposed control method more suitable for tracking control of robotic manipulators in comparison with SMC. One of these features is the model free nature of proposed control, which implies avoiding the need to determine dynamic model of the controlled system. As a second feature, control and adaption technique used in the proposed method cancels the need for determining the upper bounds of uncertainties. It should be emphasized that SMC requires the dynamic model of the system and prior knowledge of upper bound of uncertainties. Lyapunov theory is used to prove stability of proposed method and a four link SCARA robot is selected for demonstrating efficacy of the proposed method via simulation tests. Simulation tests are utilized to compare the proposed method with conventional SMC in terms of tracking control performance and cumulative error. Results have revealed significant improvement in both aspects.
\end{abstract}

Keywords: Manipulator dynamics, Sliding mode control, Robust control.

\section{Introduction}

Robotic manipulator control is among the most common yet complicated nonlinear and advanced control benchmark problems due to its nonlinearities, strong coupling among joints, and complex dynamics. Moreover, model uncertainties and external disturbances increase the difficulty to get good trajectory tracking performance for any control strategy applied on a robotic manipulator [12]. Proportional Integral Derivative (PID) controllers are widely used with linear and nonlinear systems for their structural simplicity, ease of parameter tuning, and availability of model free design procedures. In industrial applications of robotic manipulator systems, it is common practice to keep PID parameters constant, which limits the capacity of the controller to cover parameter variations, disturbances, and similar adverse influences [8, 16, 18]. For an improved performance, control systems that tune control parameters using a self-tuning PID strategy and control configurations that combine PID with a feed forward controller or a friction compensation controller are available [2, 20]. In recent years, soft computing strategies like Artificial Neural Networks (ANN) and Fuzzy Logic Control (FLC) are implemented successfully in different applications, and many researchers use FLC and ANN to tune PID parameters online [3, 6, 21]. Providing a robustperformance, SMC strategy is also focused by many researchers $[1,4,7,9,10,12$ $15,17,19,23,25]$. Despite its simplicity and easy application, SMC has its own downsides such as chattering, which can damage the controlled system and the need for prior knowledge of system dynamics. Chattering can be reduced by using saturation function instead of signum function or by employing a low pass filter in practice $[2,20]$. In addition, SMC is sensitive to parameter variations when the system state is in reaching mode because tracking error cannot be controlled directly [26]. In particular applications precise dynamic model of nonlinear systems like robotic manipulators is not available. Therefore, implementing SMC is a difficult task in many practical applications. Ability of fuzzy logic for controlling ill-defined systems and approximating nonlinear functions have motivated authors to use it by estimating parameters of the dynamic model of the controlled system. It should be noted that these schemes increase complexity of the SMC. 
Combining Proportional Derivative (PD) controller with SMC is presented in the article by Lee at al. [11]. In this hybrid method, PD control is active in reaching phase while in sliding phase SMC is active. Also Ouyang proposed a method based on PID controller and SMC for linear robotic systems [15]. In methods mentioned above, selecting the controller parameters evokes the necessity to determine the dynamic model of robotic manipulator system or upper bound of uncertainties, which in some cases is hard to achieve.

This paper combines the concepts of adaptive control, PD control, and robust control. An adaptive PD-SMC control for the robotic manipulator is presented with high robustness against system uncertainties and disturbances. PD control is proposed to replace equivalent control of SMC, which depends upon a dynamic model of the manipulator while PD is based only on the tracking error and its derivative. With this property, the proposed control scheme does not raise the need to have a dynamic model of manipulator, which makes it model free. Moreover there is no need to have prior knowledge of the upper bound of uncertainty.

\section{Robotic Manipulator Dynamics}

Structure of an n-link rigid robotic manipulator is given in Figure 1. Based on Euler-Lagrange equations the dynamics of robotic manipulator can be expressed as follows [24, 25]:

$$
\begin{aligned}
& \mathrm{M}(\mathrm{q}) \ddot{\mathrm{q}}+\mathrm{C}(\mathrm{q}, \dot{\mathrm{q}}) \dot{\mathrm{q}}+\mathrm{F}(\dot{\mathrm{q}})+\mathrm{G}(\mathrm{q})+\tau_{\mathrm{d}}=\tau(1) \\
& \mathrm{M}(\mathrm{q})=\mathrm{M}_{\mathrm{o}}(\mathrm{q})+\Delta \mathrm{M}(\mathrm{q}) \\
& \mathrm{C}(\mathrm{q}, \dot{\mathrm{q}})=\mathrm{C}_{\mathrm{o}}(\mathrm{q}, \dot{\mathrm{q}})+\Delta \mathrm{C}(\mathrm{q}, \dot{\mathrm{q}}) \\
& \mathrm{F}(\dot{\mathrm{q}})=\mathrm{F}_{\mathrm{o}}(\dot{\mathrm{q}})+\Delta \mathrm{F}(\dot{\mathrm{q}})
\end{aligned}
$$

where $q, \dot{q}, \ddot{q} \in R^{n}$ represent the position, velocity and acceleration, respectively, $M(q) \in$ $\mathrm{R}^{\mathrm{nxn}}$ is the inertia matrix, $\mathrm{C}(\mathrm{q}, \dot{\mathrm{q}}) \in \mathrm{R}^{\mathrm{nxn}}$ denotes the centrifugal-Coriolis matrix, $\mathrm{F}(\dot{\mathrm{q}}) \in$ $\mathrm{R}^{\mathrm{n}}$ stands for the friction torque vector, $\mathrm{G}(\mathrm{q}) \in$ $\mathrm{R}^{\mathrm{n}}$ represents the gravity term, $\tau_{\mathrm{d}} \in \mathrm{R}^{\mathrm{n}}$ represents the external disturbance vector, and $\tau \in \mathrm{R}^{\mathrm{n}}$ represents the input torque vector. $\mathrm{M}_{\mathrm{o}}(\mathrm{q}), \mathrm{C}_{\mathrm{o}}(\mathrm{q}, \dot{\mathrm{q}})$, and $\mathrm{F}_{\mathrm{o}}(\dot{\mathrm{q}})$ are associated with the nominal model of the robotic manipulator and $\Delta \mathrm{M}(\mathrm{q}), \Delta \mathrm{C}(\mathrm{q}, \dot{\mathrm{q}})$, and $\Delta \mathrm{F}(\dot{\mathrm{q}})$ represent the uncertainty in the dynamic model of the robotic manipulator. The important properties of robotic manipulator dynamics used in this paper are given below.

Property 1: Matrix $\dot{\mathrm{M}}(\mathrm{q})-2 \mathrm{C}(\mathrm{q}, \dot{\mathrm{q}})$ is skew matrix such that:

$\mathrm{X}^{\mathrm{T}}(\dot{\mathrm{M}}(\mathrm{q})-2 \mathrm{C}(\mathrm{q}, \dot{\mathrm{q}})) \mathrm{X}=0, \forall \mathrm{X} \in \mathrm{R}^{\mathrm{n}}$

where $\dot{M}(q)$ refers to the time derivative of the inertia matrix.

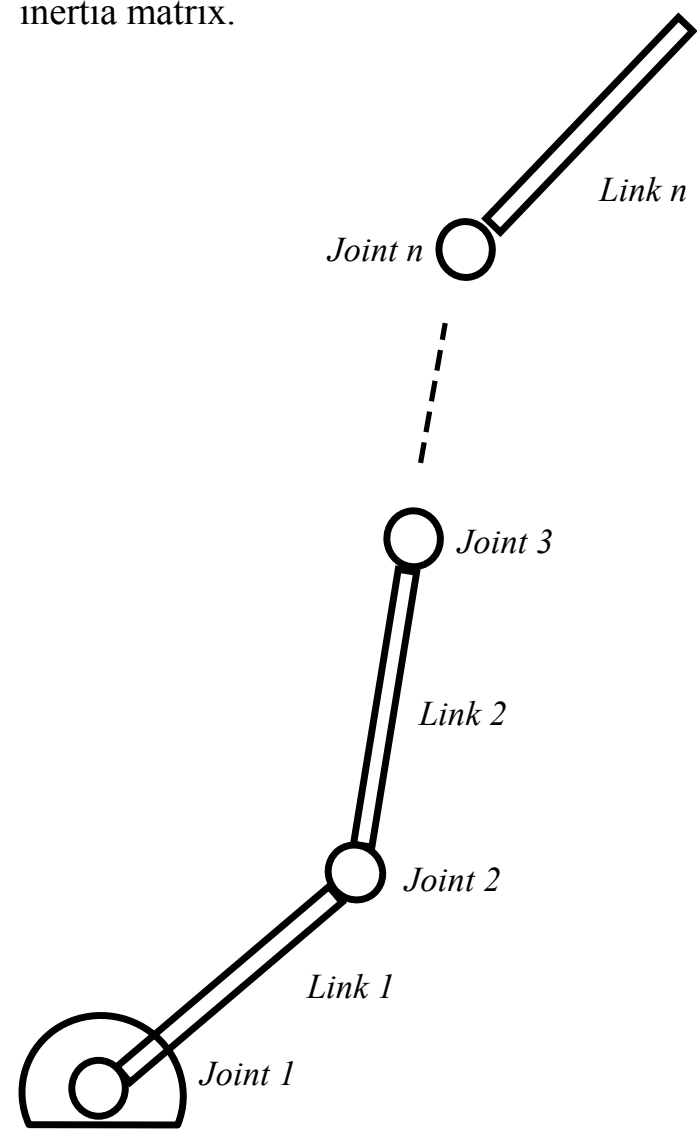

Figure 1. Schematic diagram of an $n$-link rigid robotic manipulator.

Property 2: The matrices $\mathrm{M}(\mathrm{q}), \mathrm{C}(\mathrm{q}, \dot{\mathrm{q}}), \mathrm{F}(\dot{\mathrm{q}})$ and $\mathrm{G}(\mathrm{q})$ are bounded by the following lower and/or upper limits:

$$
\begin{aligned}
& M^{-} \leq\|\mathrm{M}(\mathrm{q})\| \leq M^{+} \\
& 0 \leq C_{m}\|\mathrm{q}\|^{2} \leq\|\mathrm{C}(\mathrm{q}, \dot{\mathrm{q}}) \dot{\mathrm{q}}\| \leq C_{M}\|\mathrm{q}\|^{2} \\
& \|\mathrm{G}(\mathrm{q})\| \leq G_{M} \\
& \|\mathrm{~F}(\dot{\mathrm{q}})\| \leq F_{1}+F_{2}\|\dot{\mathrm{q}}\|
\end{aligned}
$$

where $M^{-}, M^{+}, C_{m}, C_{M}, G_{M}, F_{1}$, and $F_{2}$ are positive constants.

Property 3: Assume that the desired trajectory of joint angles is given by the vector $\mathrm{q}_{d} \in \mathrm{R}^{\mathrm{n}}$. The external disturbance $\tau_{d}$, desired joint angles $\mathrm{q}_{\mathrm{d}}$, and desired joint velocities $\dot{\mathrm{q}}_{\mathrm{d}}$ are bounded as follows:

$$
\left\|\tau_{\mathrm{d}}\right\| \leq \tau_{M}
$$


$\left\|\mathrm{q}_{\mathrm{d}}\right\| \leq A_{M}$

$\left\|\dot{\mathrm{q}}_{\mathrm{d}}\right\| \leq V_{M}$

where $\tau_{M}, A_{M}$ and $V_{M}$ are positive constants.

\section{SMC for Robotic Manipulator}

In robotic manipulator control design, the tracking error $\mathrm{e}(\mathrm{t}) \in \mathrm{R}$ is the deviation between the desired trajectory vector and the actual trajectory vector. The sliding surface is selected as follows:

$S(\mathrm{t})=\gamma \mathrm{e}(\mathrm{t})+\dot{\mathrm{e}}(\mathrm{t})$

with $\gamma \in \mathrm{R}^{\mathrm{nxn}}$ being a positive diagonal matrix. The SMC control law consists of equivalent control term and robust term. The equivalent control term is responsible for the performance with nominal model of controlled system and it is determined by making derivative of sliding surface equal to zero. The derivative of the sliding surface is

$\dot{\mathrm{S}}(\mathrm{t})=\gamma \dot{\mathrm{e}}(\mathrm{t})+\ddot{\mathrm{e}}(\mathrm{t})$

$\ddot{\mathrm{e}}(\mathrm{t})=\ddot{\mathrm{q}}_{\mathrm{d}}-\ddot{\mathrm{q}}$

$\ddot{\mathrm{q}}=\mathrm{M}^{-1}(\mathrm{q})\left[-\mathrm{C}(\mathrm{q}, \dot{\mathrm{q}}) \dot{\mathrm{q}}-\mathrm{F}(\dot{\mathrm{q}})-\mathrm{G}(\mathrm{q})-\tau_{\mathrm{d}}+\right.$

$\tau]$

Define a nominal reference $\dot{\mathrm{q}}_{\mathrm{r}}$ :

$\dot{\mathrm{q}}_{\mathrm{r}}=\dot{\mathrm{q}}_{\mathrm{d}}+\gamma\left(\mathrm{q}_{\mathrm{d}}-\mathrm{q}\right)$

By simple calculations one can be obtain the following:

$\dot{\mathrm{S}}(\mathrm{t})=\dot{\mathrm{q}}_{\mathrm{r}}-\dot{\mathrm{q}}$

$\ddot{S}(\mathrm{t})=\ddot{q}_{\mathrm{r}}-\ddot{\mathrm{q}}$

The dynamic model of the robotic manipulator is linearly parameterized and can be expressed in terms of a nominal reference, $\dot{\mathrm{q}}_{\mathrm{r}}$ [17].

$\mathrm{Y} \beta=\mathrm{M}(\mathrm{q}) \ddot{\mathrm{q}}_{\mathrm{r}}+\mathrm{N}(\mathrm{q}, \dot{\mathrm{q}}) \dot{\mathrm{q}}_{\mathrm{r}}+\mathrm{G}(\mathrm{q})+\mathrm{H}(\dot{\mathrm{q}})(20)$ where $Y=Y\left(q, \dot{\mathrm{q}}, \dot{\mathrm{q}}_{\mathrm{r}}, \ddot{\mathrm{q}}_{\mathrm{r}}\right) \in \mathrm{R}^{\mathrm{n} \times \mathrm{p}} \quad$ is the dynamic regression matrix that contains a known nonlinear function, $\beta \in \mathrm{R}^{\mathrm{p}}$ is a vector that contains unknown constant parameters. Let us consider that:

$\rho(\mathrm{t})=\mathrm{Y} \beta$

The control term which is called equivalent control in SMC is determined by setting

$\dot{\mathrm{S}}(\mathrm{t})=0$

without any uncertainties and only nominal dynamic is used as follows:

$$
\begin{gathered}
\mathrm{u}_{\mathrm{eq}}=\mathrm{M}_{\mathrm{o}}(\mathrm{q})\left[\ddot{\mathrm{q}}_{\mathrm{d}}+\gamma \dot{\mathrm{e}}(\mathrm{t})\right] \\
+\left[\mathrm{C}_{\mathrm{o}}(\mathrm{q}, \dot{\mathrm{q}}) \dot{\mathrm{q}}+\mathrm{F}_{\mathrm{o}}(\dot{\mathrm{q}})+\mathrm{G}_{\mathrm{o}}(\mathrm{q})\right]
\end{gathered}
$$

In (21) only nominal model of robotic manipulator is used without external disturbance and without system uncertainties. Therefore, SMC method adds robust term to compensate for the uncertainties of the controlled system and external disturbance. Then the SMC control law can be expressed as:

$\mathrm{u}=\mathrm{u}_{\mathrm{eq}}+\mathrm{u}_{\mathrm{s}}$

where $u_{\text {eq }}$ is equivalent control that makes the sliding surface derivative zero for staying on the sliding surface and $u_{s}$ is corrective control that is for compensation of deviations from it. The robust term, which is also called hitting control or reaching control, is determined based on Lyapunov stability theory as given in following equation:

$\mathrm{u}_{\mathrm{s}}=\mathrm{k} \operatorname{sign}(\mathrm{s})$

where $\mathrm{k}=\mathrm{f}(\mathrm{q}, \dot{\mathrm{q}}, \mathrm{M}(\mathrm{q}), \mathrm{C}(\mathrm{q}, \dot{\mathrm{q}}), \mathrm{F}(\dot{\mathrm{q}}), \mathrm{G}(\mathrm{q}))$ and sign(.) is sign function. This leads to the fact that determining a suitable value for $\mathrm{k}$ is a difficult task since it requires having the nominal part and uncertainty part of the robotic manipulator dynamics and it is required to be greater than the upper bound of the uncertainty.

\section{PD with SMC}

In order to provide a solution to the problem of lack of accuracy in dynamic model of the system to be controlled in SMC design, a robust model free control law [14] is used as follows:

$\tau=k_{p} \mathrm{e}+k_{d} \dot{\mathrm{e}}(\mathrm{t})+k \operatorname{sat}(\mathrm{S}, \emptyset)$

$\operatorname{sat}(\mathrm{S}, \emptyset)= \begin{cases}\operatorname{sign}(\mathrm{S}) & \text { if }|\mathrm{S}|>\varnothing \\ \mathrm{S} / \varnothing & \text { if }|\mathrm{S}| \leq \varnothing\end{cases}$

where $k_{p} \in \mathrm{R}^{\mathrm{n} \times \mathrm{n}}$ and $k_{d} \in \mathrm{R}^{\mathrm{n} \times \mathrm{n}}$ are positive diagonal proportional and derivative matrices gains respectively, $k$ is the gain of the robust term, and $\varnothing$ represents the boundary layers that are used in sat function, which is utilized instead of sign function that causes chattering due to its discontinuity. With this preference of sign function instead of sat function, the states remain at boundary layer neighborhood.

As a result, switching control is used when the state is outside of boundary layer and becomes standard feedback control when inside boundary layer. This helps in eliminating the chattering phenomenon in corrective signal. 
Remark 1: By an inspection of the control law in (26) in conjunction with the SMC control law in (23-25), one can conclude that there is no dynamic parameter in the control law, which makes it model free.

Remark 2: The control law combines robustness features of SMC and ability of PD control in tracking with fast response, which is verified by simulation results in subsequent section.

Theorem 1: Consider the nonlinear robotic manipulator model represented by the dynamic system in (1) with the assumptions addressed in (5-12). The system that is controlled using the control law in (26) is globally stable and the tracking error signal and its derivative both converge to zero when the controller parameters are selected to satisfy the following condition:

Proof: For the verification of stability, the positive definite Lyapunov function candidate given below is used.

$$
\begin{aligned}
& \mathrm{V}(\mathrm{t})=\frac{1}{2} \mathrm{~S}^{\mathrm{T}} \mathrm{MS} \\
& \dot{\mathrm{V}}(\mathrm{t})=\mathrm{S}^{\mathrm{T}} \mathrm{MS}+\frac{1}{2} \mathrm{~S}^{\mathrm{T}} \dot{\mathrm{M} S} \\
& =\mathrm{S}^{\mathrm{T}} \mathrm{MS}+\mathrm{S}^{\mathrm{T}} \mathrm{CS} \\
& =\mathrm{S}^{\mathrm{T}}\left[\mathrm{M}\left(\ddot{\mathrm{q}}_{\mathrm{r}}-\ddot{\mathrm{q}}\right)+\mathrm{C}\left(\dot{\mathrm{q}}_{\mathrm{r}}-\dot{\mathrm{q}}\right)\right] \\
& =\mathrm{S}^{\mathrm{T}}\left[\mathrm{M} \ddot{\mathrm{q}}_{\mathrm{r}}+\mathrm{C} \dot{\mathrm{q}}_{\mathrm{r}}-\mathrm{M} \ddot{\mathrm{q}}-\mathrm{C} \dot{\mathrm{q}}\right] \\
& =\mathrm{S}^{\mathrm{T}}\left[\mathrm{M} \ddot{\mathrm{q}}_{\mathrm{r}}+\mathrm{C} \dot{\mathrm{q}}_{\mathrm{r}}+\mathrm{G}-\tau\right] \\
& =\mathrm{S}^{\mathrm{T}}\left[\mathrm{M} \ddot{\mathrm{q}}_{\mathrm{r}}+\mathrm{C} \dot{\mathrm{q}}_{\mathrm{r}}+\mathrm{G}-k_{p} \mathrm{e}-k_{d} \dot{\mathrm{e}}(\mathrm{t})-\right. \\
& k \operatorname{sat}(\mathrm{S}, \emptyset)] \\
& =\mathrm{S}^{\mathrm{T}}\left[\rho(\mathrm{t})-k_{p} \mathrm{e}-k_{d} \dot{\mathrm{e}}(\mathrm{t})-k \operatorname{sat}(\mathrm{S}, \emptyset)\right]
\end{aligned}
$$

If parameters $k_{p}$ and $k_{d}$ selected as follows

$k_{d}{ }^{-1} k_{p}=\gamma$

then (30) becomes

$$
\begin{aligned}
& \dot{\mathrm{V}}(\mathrm{t})=\mathrm{S}^{\mathrm{T}}\left[\rho(\mathrm{t})-k_{d} \mathrm{~S}-k \operatorname{sat}(\mathrm{S}, \emptyset)\right] \\
& =-\mathrm{S}^{\mathrm{T}} k_{d} \mathrm{~S}+\mathrm{S}^{\mathrm{T}}[\rho(\mathrm{t})-k \operatorname{sat}(\mathrm{S}, \emptyset)] \\
& \leq-\mathrm{S}^{\mathrm{T}} k_{d} \mathrm{~S}-\|k\|\|\mathrm{S}\|+\|\rho(\mathrm{t})\|\|\mathrm{S}\|
\end{aligned}
$$

If $k$ selected large enough greater than $\rho(t)$, then

$\dot{\mathrm{V}}(\mathrm{t})=-\mathrm{S}^{\mathrm{T}} k_{d} \mathrm{~S}$

which implies that:

$\dot{\mathrm{V}}(\mathrm{t}) \leq 0$

Since the function $V(t)$ is a positive definite function and its derivative is negative, the controlled system in (1) with the control law in
(26) is asymptotically stable with tracking error signal and its derivative converging to zero.

Remark 3: In the control law in (26), there is a big drawback because approving stability of this method requires selecting controller parameter $k$ to be larger than $\rho(\mathrm{t})$ and magnitude of $\rho(t)$ depends on mechanical properties of robotic manipulator such as joint angles, velocities, and upper bound of uncertainty. In general, determining the upper bound of uncertainty is difficult.

Remark 4: The problem of the necessity of determining the upper bound of uncertainty can be solved using the adaption technique discussed in Theorem 2 to adapt the controller parameters $k$.

\section{Proposed Control Design}

Theorem 2: For the robotic manipulator system in (1) with the control law expressed by (24), the closed-loop system is guaranteed to be globally stable if the following proposed adaptive control law is used:

$\tau=k_{p} \mathrm{e}+k_{d} \dot{\mathrm{e}}(\mathrm{t})+\hat{\rho}$

where $\hat{\rho} \in \mathrm{R}^{1 \times \mathrm{n}}$ represents estimation for $\rho(t)$ that defined in (21). $\tilde{\rho} \in \mathrm{R}^{1 \times \mathrm{n}}$ is the estimation error which can be determined as follows:

$\tilde{\rho}(t)=\rho(t)-\hat{\rho}(t)$

The adaptation law is given by:

$\dot{\tilde{\rho}}=-\mathrm{L}^{\mathrm{T}} \mathrm{S}$

where $\mathrm{L} \in \mathrm{R}^{\mathrm{n} \times \mathrm{n}}$ is the diagonal matrix adaptation rate. Then $\hat{\rho}(t)$ can be updated based on the following:

$\hat{\rho}(t)=\int_{t-1}^{t} \dot{\tilde{\rho}}(t) d t+\hat{\rho}(t-1)$

Proof: The Lyapunov function candidate $\mathrm{V}(\mathrm{t})$ is used for the verification of stability. This function is composed of $\mathrm{n}$ terms that are known to be all positive definite as given in (27). Each of these components of the Lyapunov function candidates is given by:

$$
\begin{aligned}
& \mathrm{V}(\mathrm{t})=\frac{1}{2}\left[\mathrm{~S}^{\mathrm{T}} \mathrm{MS}+\tilde{\rho}^{T} \mathrm{~L}^{-1} \tilde{\rho}\right] \\
& \dot{\mathrm{V}}(\mathrm{t})=\mathrm{S}^{\mathrm{T}} \mathrm{MS}+\frac{1}{2} \mathrm{~S}^{\mathrm{T}} \dot{\mathrm{M} S}+\dot{\tilde{\rho}}^{T} \mathrm{~L}^{-1} \tilde{\rho} \\
& =\mathrm{S}^{\mathrm{T}} \mathrm{MS}+\mathrm{S}^{\mathrm{T}} \mathrm{CS}+\dot{\tilde{\rho}}^{T} \mathrm{~L}^{-1} \tilde{\rho} \\
& =\mathrm{S}^{\mathrm{T}}\left[\mathrm{M}\left(\ddot{\mathrm{q}}_{\mathrm{r}}-\ddot{\mathrm{q}}\right)+\mathrm{C}\left(\dot{\mathrm{q}}_{\mathrm{r}}-\dot{\mathrm{q}}\right)\right]+\dot{\tilde{\rho}}^{T} \mathrm{~L}^{-1} \tilde{\rho} \\
& =\mathrm{S}^{\mathrm{T}}\left[\mathrm{M} \ddot{\mathrm{q}}_{\mathrm{r}}+\mathrm{C} \dot{\mathrm{q}}_{\mathrm{r}}-\mathrm{M} \ddot{\mathrm{q}}-\mathrm{C} \dot{\mathrm{q}}\right]+\dot{\tilde{\rho}}^{T} \mathrm{~L}^{-1} \tilde{\rho}
\end{aligned}
$$




$$
=S^{\mathrm{T}}\left[M \ddot{q}_{\mathrm{r}}+C \dot{\mathrm{q}}_{\mathrm{r}}+\mathrm{G}-\tau\right]
$$

$=\mathrm{S}^{\mathrm{T}}\left[\mathrm{M} \ddot{q}_{\mathrm{r}}+\mathrm{C} \dot{\mathrm{q}}_{\mathrm{r}}+\mathrm{G}-k_{p} \mathrm{e}-k_{d} \dot{\mathrm{e}}(\mathrm{t})-\hat{\rho}\right]+$ $\dot{\tilde{\rho}}^{T} \mathrm{~L}^{-1} \tilde{\rho}$

$=\mathrm{S}^{\mathrm{T}}\left[\rho(t)-k_{p} \mathrm{e}-k_{d} \dot{\mathrm{e}}(\mathrm{t})-\hat{\rho}\right]$

$+\dot{\tilde{\rho}}^{T} \mathrm{~L}^{-1} \tilde{\rho}$

If parameters $k_{p}$ and $k_{d}$ selected based on condition in (36) then,

$\dot{\mathrm{V}}(\mathrm{t})=\mathrm{S}^{\mathrm{T}}\left[\rho(t)-k_{d} \mathrm{~S}-\hat{\rho}(t) s\right]$

$+\dot{\tilde{\rho}}^{T} \mathrm{~L}^{-1} \tilde{\rho}$

$=-\mathrm{S}^{\mathrm{T}} k_{d} \mathrm{~S}+\mathrm{S}^{\mathrm{T}}[\rho(t)-\hat{\rho}(t)]+\dot{\tilde{\rho}}^{T} \mathrm{~L}^{-1} \tilde{\rho}$

$\leq-\mathrm{S}^{\mathrm{T}} k_{d} \mathrm{~S}+\mathrm{S}^{\mathrm{T}}[\tilde{\rho}]+\dot{\tilde{\rho}}^{T} \mathrm{~L}^{-1} \tilde{\rho}$

$\leq-S^{\mathrm{T}} k_{d} S+S^{\mathrm{T}}[\tilde{\rho}]+\dot{\tilde{\rho}}^{T} \mathrm{~L}^{-1} \tilde{\rho}$

$\leq-\mathrm{S}^{\mathrm{T}} k_{d} \mathrm{~S}+\left[\mathrm{S}^{\mathrm{T}}+\dot{\tilde{\rho}}^{T} \mathrm{~L}^{-1}\right] \tilde{\rho}$

If changing rate of the control parameter is selected as given in (59):

$\dot{\tilde{\rho}}=-\mathrm{L}^{\mathrm{T}} \mathrm{S}$

$\dot{\mathrm{V}}(\mathrm{t})=-\mathrm{S}^{\mathrm{T}} k_{d} \mathrm{~S} \leq 0$

\section{Simulation Results}

This section demonstrates the effectiveness of proposed control method via simulation tests using a 4DOF SCARA robot manipulator with the schematic diagram in Figure 2 and the dynamic model represented by (61-66) [22]

$$
\begin{aligned}
& P_{1}=\sum_{i=1}^{4} I_{i}+m_{1} x_{1}^{2}+m_{2}\left(x_{2}^{2}+a_{1}^{2}\right) \\
& +\left(m_{3}+m_{4}\right)\left(a_{2}^{2}+a_{1}^{2}\right) \\
& P_{2}=2\left[a_{1} x_{2} m_{2}+a_{1} a_{2}\left(m_{3}+m_{4}\right)\right] \\
& P_{3}=\sum_{i=2}^{4} I_{i}+m_{2} x_{2}^{2}+a_{2}^{2}\left(m_{3}+m_{4}\right) \\
& P_{4}=m_{3}+m_{4} \\
& P_{5}=I_{4}
\end{aligned}
$$

where $q_{1}, q_{2}, q_{3}$ and $q_{4}$ are angular positions, $\tau_{1}, \tau_{2}, \tau_{3}$ and $\tau_{4}$ are torques, $a_{1}$ and $a_{2}$ are lengths, $m_{1}, m_{2}, m_{3}$ and $m_{4}$ are masses, $I_{1}, I_{2}$, $I_{3}$ and $I_{4}$ are moments of inertia, $v_{1}, v_{2}, v_{3}$ and $v_{4}$ are coefficients of viscous friction, and $h_{1}$, $h_{2}, h_{3}$ and $h_{4}$ are coefficients of dynamic friction of the three links, respectively.

$$
\begin{gathered}
{\left[\begin{array}{l}
\tau_{1} \\
\tau_{2} \\
\tau_{3} \\
\tau_{4}
\end{array}\right]=\left[\begin{array}{cccc}
P_{1}+P_{2} c_{2} & P_{1}+P_{2} c_{2} & 0 & -P_{5} \\
P_{3}+0.5 P_{2} c_{2} & P_{3} & 0 & -P_{5} \\
0 & 0 & P_{4} & 0 \\
-P_{5} & -P_{5} & 0 & P_{5}
\end{array}\right]\left[\begin{array}{l}
\ddot{q}_{1} \\
\ddot{q}_{2} \\
\ddot{q}_{3} \\
\ddot{q}_{4}
\end{array}\right]+\left[\begin{array}{cccc}
-P_{2} s_{2} \dot{q}_{2} & -0.5 P_{2} s_{2} \dot{q}_{2} & 0 & 0 \\
0.5 P_{2} s_{2} \dot{q}_{1} & 0 & 0 & 0 \\
0 & 0 & 0 & 0 \\
0 & 0 & 0 & 0
\end{array}\right]\left[\begin{array}{c}
\dot{q}_{1} \\
\dot{q}_{2} \\
\dot{q}_{3} \\
\dot{q}_{3}
\end{array}\right]} \\
+\left[\begin{array}{c}
v_{1} \dot{q}_{1} \\
v_{2} \dot{q}_{2} \\
v_{3} \dot{q}_{3} \\
v_{4} \dot{q}_{4}
\end{array}\right]+\left[\begin{array}{l}
h_{1} \operatorname{sgn}\left(\dot{q}_{1}\right) \\
h_{2} \operatorname{sgn}\left(\dot{q}_{2}\right) \\
h_{3} \operatorname{sgn}\left(\dot{q}_{3}\right) \\
h_{4} \operatorname{sgn}\left(\dot{q}_{4}\right)
\end{array}\right]+\left[\begin{array}{c}
0 \\
0 \\
P_{4} g \\
0
\end{array}\right]
\end{gathered}
$$

Then the proposed adaptation law for tuning the proposed controller guarantees asymptotic stability of the robotic manipulator in (1) with tracking error signal and its derivative converging to zero.

Table 1 summarizes the requirements of SMC, PD with SMC and proposed method. It is evident from this table that the proposed method does not urge the need for any a priori knowledge of plant dynamics or uncertainty bounds, which makes it more suitable for control of complicated dynamical mechanisms including robotic manipulators
Table 1. Requirements of control methods

\begin{tabular}{|c|c|c|}
\hline Method & $\begin{array}{c}\text { Exact } \\
\text { dynamic model }\end{array}$ & $\begin{array}{c}\text { Upper bound of } \\
\text { uncertainty }\end{array}$ \\
\hline SMC & Yes & Yes \\
\hline PD with SMC & No & Yes \\
\hline $\begin{array}{c}\text { Proposed } \\
\text { Method }\end{array}$ & No & No \\
\hline
\end{tabular}


The parameters of the robotic manipulator are selected for the simulation tests as given in Table 2 [22].

Table 2. Manipulator Parameters

\begin{tabular}{|c|c|}
\hline parameter & value \\
\hline$m_{1}$ & $15 \mathrm{~kg}$ \\
\hline$m_{2}$ & $12 \mathrm{~kg}$ \\
\hline$m_{3}$ & $3 \mathrm{~kg}$ \\
\hline$m_{4}$ & $3 \mathrm{~kg}$ \\
\hline$I_{1}$ & $0.02087 \mathrm{~kg} \cdot \mathrm{m}^{2}$ \\
\hline$I_{2}$ & $0.087 \mathrm{~kg} \cdot \mathrm{m}^{2}$ \\
\hline$I_{3}$ & $0.05 \mathrm{~kg} \cdot \mathrm{m}^{2}$ \\
\hline$I_{4}$ & $0.02 \mathrm{~kg} \cdot \mathrm{m}^{2}$ \\
\hline$a_{1}$ & $0.5 \mathrm{~m}$ \\
\hline$a_{2}$ & $0.4 \mathrm{~m}$ \\
\hline$x_{1}$ & $0.25 \mathrm{~m}$ \\
\hline$x_{2}$ & $0.2 \mathrm{~m}$ \\
\hline$v_{1}, v_{2}, v_{3}, v_{4}$ & $5 \mathrm{Nm} . \mathrm{s}$ \\
\hline$h_{1}, h_{2}, h_{3}, h_{4}$ & $10 \mathrm{Nm}$ \\
\hline
\end{tabular}

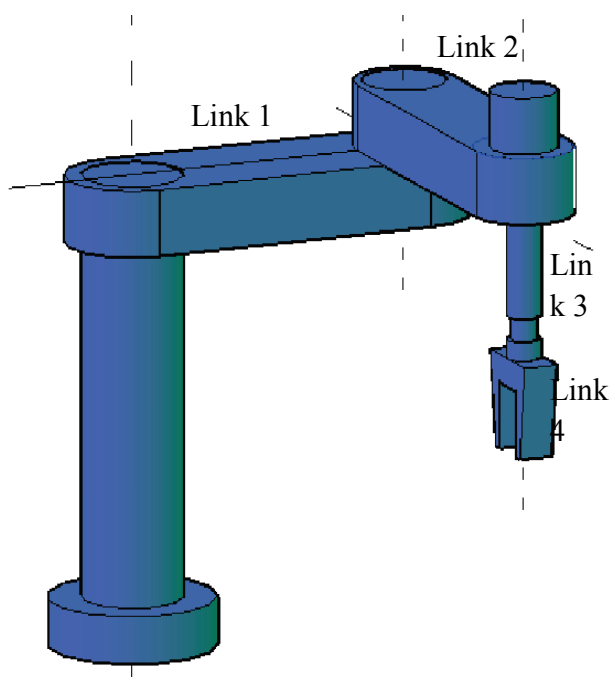

Figure 2. Schematic diagram of the 4DOF

SCARA robot.

The desired joint trajectories in this simulation are selected to be sinusoidal variations versus time as $\mathrm{q}_{\mathrm{d}}(\mathrm{t})=\left[\begin{array}{llll}q_{d 1} & q_{d 2} & q_{d 3} & q_{d 4}\end{array}\right]^{T}$, where

$$
\begin{aligned}
& q_{d 1}=-0.2+0.1 \sin (t) \\
& q_{d 2}=0.3+0.1 \cos (t) \\
& q_{d 3}=-0.3+0.1 \cos (t) \\
& q_{d 4}=0.1+0.1 \cos (t)
\end{aligned}
$$

As a demonstration of the efficacy and performance of proposed scheme, it is tested via simulation comparatively with conventional SMC. Integral Absolute Error (IAE) type of error criterion in (71) is used to assess the effectiveness of control schemes in terms of cumulative error.

$I A E=\int_{0}^{t f}|\mathrm{e}(\mathrm{t})| d t$

In design of controller parameters, first the positive definite matrix $\gamma$ is selected, and then according to condition in (36) the values of control gains in matrices $k_{p}$ and $k_{d}$ are determined. As a result, the parameters take the values of $\gamma=5 \mathrm{I}_{4}, k_{p}=300 \mathrm{I}_{4}$, and $k_{d}=60 \mathrm{I}_{4}$. $\emptyset=0.02 \mathrm{I}_{4}$. Finally the controller parameter vector $\hat{\rho}$ is updated according to (45) with initial value $\hat{\rho}(0)=\left[\begin{array}{llll}0.01 & 01 & 0.06 & 0.02\end{array}\right]^{T}$ where adaption rate matrix is $\mathrm{L}=100 \mathrm{I}_{4}$.

The effectiveness and robustness of the proposed control method are investigated under model uncertainties and compared with the SMC as shown in Figures 3-7.
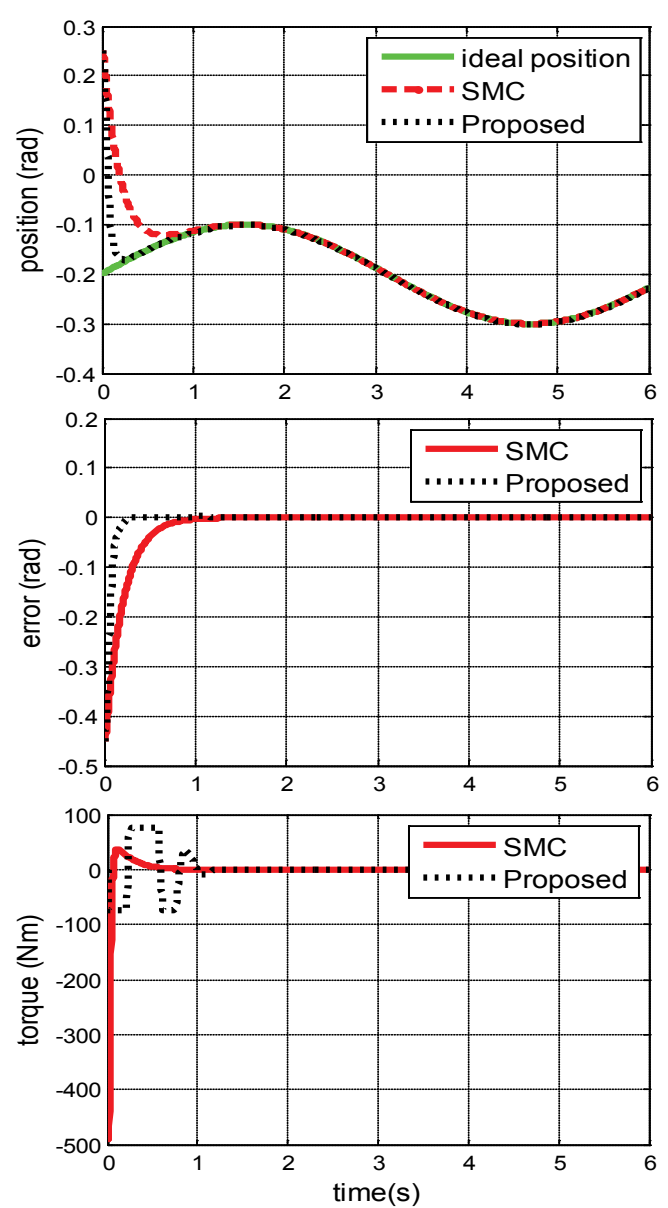

Figure 3. Angular position (a), tracking error (b), and input torque (c) of Link 1 versus time in response to model uncertainty 

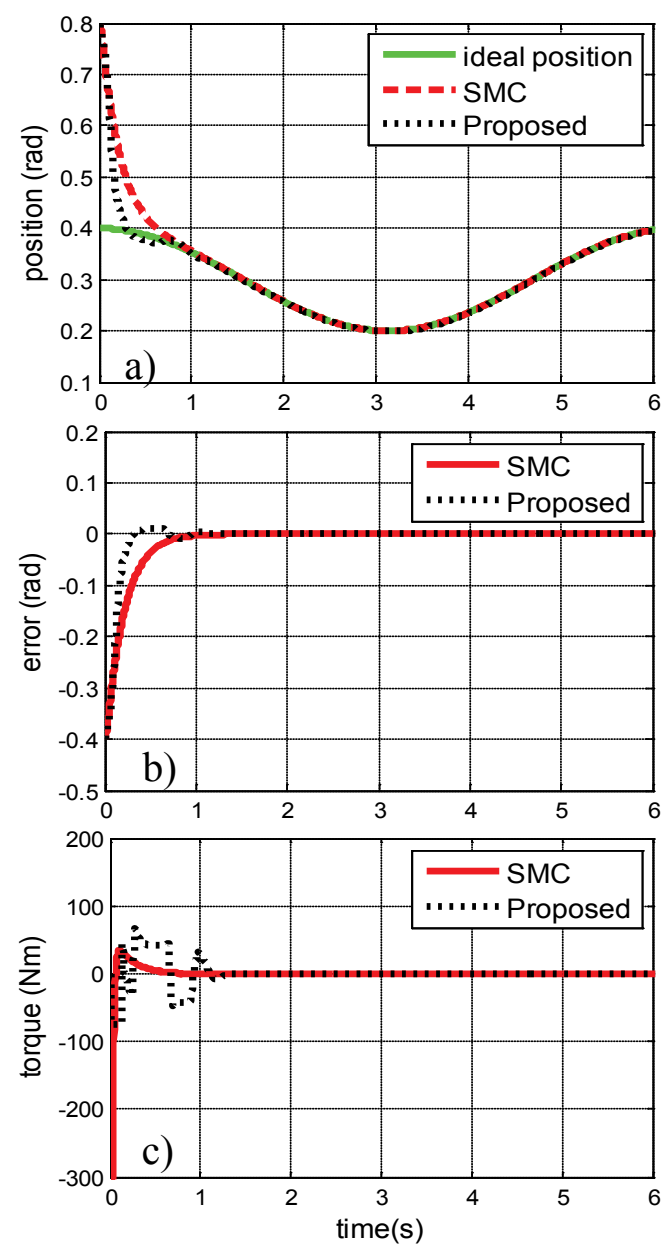

Figure 4. Angular position (a), tracking error (b), and input torque (c) of Link 2 versus time in response to model uncertainty

The model uncertainties include variations of manipulator parameters namely mass, constant friction, and dynamic friction of Link1, Link2 and Link3. In this simulation the parameters are changed as much as $15 \%$ of their nominal values. From Figures 3, 4, 5 and 6 it is observed that the proposed control method has satisfactory tracking performance with significantly reduced position tracking errors with respect to standard SMC. Moreover, these graphs in figures are clear indications of faster response of the method being proposed. The control input torque signals versus simulation time for Link1, Link2, Link3 and Link4 are shown in associated Figures 3-c, 4-c, 5-c and 6c, respectively.

Results that are graphically presented in these figures indicate that the control efforts of proposed control method and those of standard SMC are approximately equal for all three links with the exception of a temporary transient duration at the beginning of simulation. Table 3 and Figure 7 present the $I A E$ values for proposed control scheme and conventional SMC.

Proposed method reduces the cumulative error to approximately $30 \%$ of that of the standard SMC. These values of the $I A E$ index are clear indications of superiority of proposed control scheme in reducing cumulative tracking error in addition to significant reduction in the control effort.
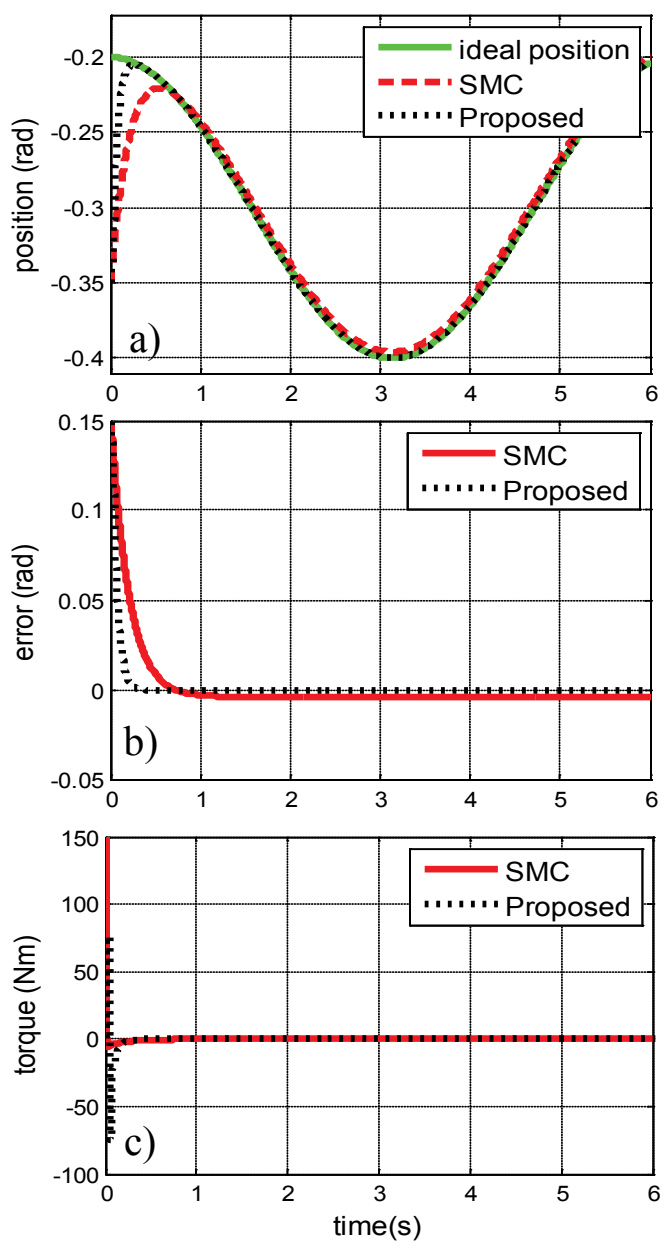

Figure 5. Angular position (a), tracking error (b), and input torque (c) of Link 3 versus time in response to model uncertainty

Table 3 Performance index $I A E$ values

\begin{tabular}{|l|c|c|}
\hline & Proposed & SMC \\
\hline Link1 & 0.0122 & 0.0142 \\
\hline Link2 & 0.0176 & 0.0197 \\
\hline Link3 & 0.0031 & 0.0052 \\
\hline Link4 & 0.0017 & 0.0030 \\
\hline
\end{tabular}



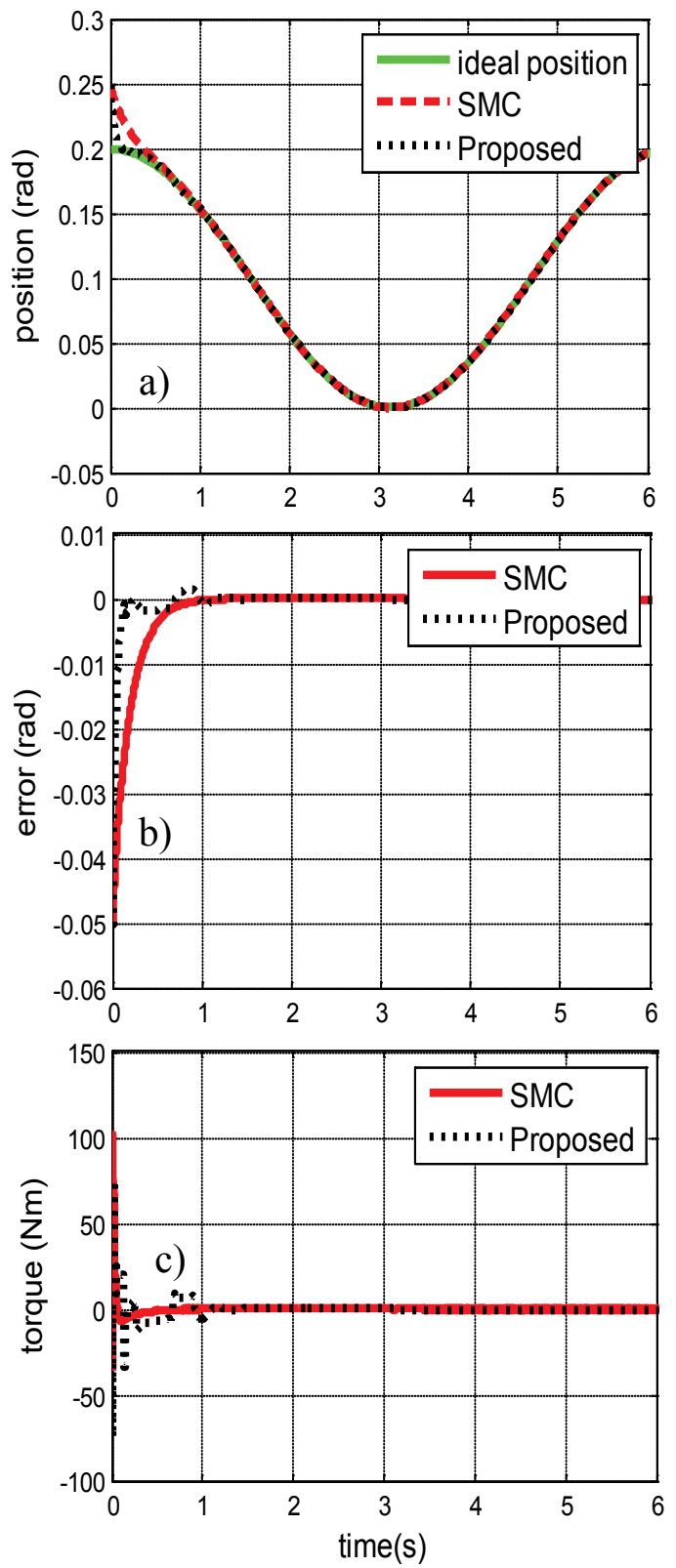

Figure 6. Angular position (a), tracking error (b), and input torque (c) of Link 4 versus time in response to model uncertainty

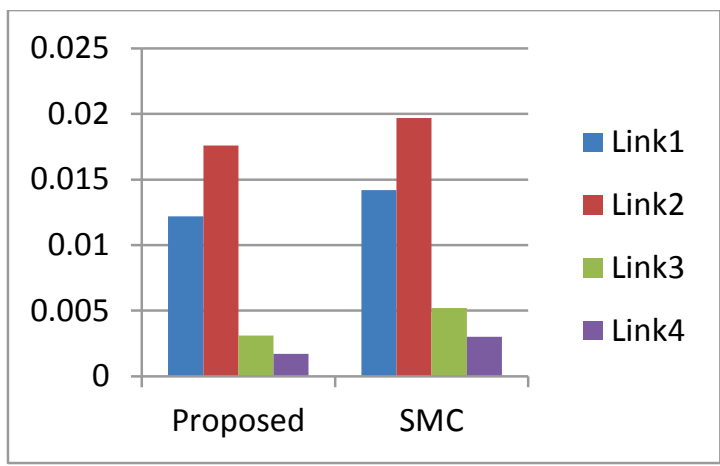

Figure 7. $I A E$ variations for model uncertainties

\section{Conclusion}

In this study an adaptive PD-SMC scheme for robotic manipulators is proposed where controller parameter design is based on Lyapunov method. Unlike conventional SMC that requires having the dynamic model of the manipulator or other methods that are based on prior knowledge of upper bound of uncertainties, the proposed method is totally model free. The stability of the general robotic manipulator system with proposed control scheme is proved and its performance is revealed by simulation tests on a 4DOF SCARA robotic manipulator. Test results are presented in graphical form and in terms of the $I A E$ performance index. Results reveal significantly better nonlinear robotic manipulator tracking performance by proposed method as well as reduced cumulative error represented by IAE over standard SMC.

\section{REFERENCES}

1. Ajwad, S. A., Iqbal, J., Khan, A. A., \& Mehmood, A. (2015). Disturbanceobserver-based robust control of a seriallink robotic manipulator using SMC and PBC techniques, Studies in Informatics and Control, 24(4), pp. 401-408.

2. Astrom, K. J. \& Wittenmark, B. (2008). Adaptive Control, Dover.

3. Cerman, O., \& Hušek, P. (2012). Adaptive fuzzy sliding mode control for electrohydraulic servo mechanism, Expert Systems with Applications, 39(11), pp. 10269-10277.

4. Chen, C. Y., Li, T. H. S., \& Yeh, Y. C. (2009). EP-based kinematic control and adaptive fuzzy sliding-mode dynamic control for wheeled mobile robots, Information Sciences, 179(1), pp. 180-195.

5. Craig, J. (2014). Introduction to robotics: mechanics and control, Addison Wesley Publishing, Massachusetts, MA, pp. 171-192.

6. D'Emilia, G., Marra, A., \& Natale, E. (2007). Use of neural networks for quick and accurate auto-tuning of PID controller, Robotics and Computer-Integrated Manufacturing, 23(2), pp. 170-179. 
7. Ferrara, A., \& Magnani, L. (2007). Motion control of rigid robot manipulators via first and second order sliding modes, Journal of Intelligent \& Robotic Systems, 48(1), pp. 23-36.

8. Ghosh, B. B., Sarkar, B. K., \& Saha, R. (2015). Realtime performance analysis of different combinations of fuzzy-PID and bias controllers for a two degree of freedom electrohydraulic parallel manipulator, Robotics and ComputerIntegrated Manufacturing, 34, pp. 62-69.

9. Kuo, C. L., Li, T. H. S., \& Guo, N. R. (2005). Design of a novel fuzzy slidingmode control for magnetic ball levitation system, Journal of Intelligent \& Robotic Systems, 42(3), pp. 295-316.

10. Lee, K. J., Choi, J. J., \& Kim, J. S. (2004). A proportional-derivative-sliding mode hybrid control scheme for a robot manipulator, Proceedings of the Institution of Mechanical Engineers, Part I: Journal of Systems and Control Engineering, 218(8), pp. 667-674.

11. Li, T. H. S., \& Huang, Y. C. (2010). MIMO adaptive fuzzy terminal slidingmode controller for robotic manipulators, Information Sciences, 180(23), pp. 4641-4660.

12. Liang, Y. W., Xu, S. D., Liaw, D. C., \& Chen, C. C. (2008). A study of T-S model-based SMC scheme with application to robot control, IEEE Transactions on Industrial Electronics, 55(11), pp. 3964-3971.

13. Liu, Y., \& Li, Y. (2005). Sliding mode adaptive neural-network control for nonholonomic mobile modular manipulators, Journal of Intelligent \& Robotic Systems, 44(3), pp. 203-224.

14. Ouyang, P. R., Acob, J., \& Pano, V. (2014). PD with sliding mode control for trajectory tracking of robotic system, Robotics and Computer-Integrated Manufacturing, 30(2), pp. 189-200.

15. Parnichkun, M., \& Ngaecharoenkul, C. (2000). Hybrid of fuzzy and PID in kinematics control of a pneumatic system, In Industrial Electronics Society, 2000.
IECON 2000. 26th Annual Conference of the IEEE (Vol. 2, pp. 1485-1490). IEEE.

16. Parra-Vega, V., Arimoto, S., Liu, Y. H., Hirzinger, G., \& Akella, P. (2003). Dynamic sliding PID control for tracking of robot manipulators: Theory and experiments, IEEE Transactions on Robotics and Automation, 19(6), pp. 967-976.

17. Pratumsuwan, P., Thongchai, S., \& Tansriwong, S. (2010). A hybrid of fuzzy and proportional-integral-derivative controller for electro-hydraulic position servo system, Energy Research Journal, 1(2), pp. 62-67.

18. Roopaei, M., \& Jahromi, M. Z. (2009). Chattering-free fuzzy sliding mode control in MIMO uncertain systems, Nonlinear Analysis: Theory, Methods \& Applications, 71(10), pp. 4430-4437.

19. Sadati, N., \& Ghadami, R. (2008). Adaptive multi-model sliding mode control of robotic manipulators using soft computing, Neurocomputing, 71(13), pp. 2702-2710.

20. Song, S., \& Liu, W. (2006, November). Fuzzy parameters self-tuning PID control of switched reluctance motor based on Simulink/NCD, In Computational Intelligence for Modelling, Control and Automation, 2006 and International Conference on Intelligent Agents, Web Technologies and Internet Commerce, International Conference, pp. 73-73. IEEE

21. Su, Y. X., \& Zheng, C. H. (2010). Global asymptotic tracking of robot manipulators with a simple decentralised non-linear PDlike controller, IET control theory \& applications, 4(9), pp. 1605-1611.

22. Voglewede, P., Smith, A. H., \& Monti, A. (2009). Dynamic performance of a SCARA robot manipulator with uncertainty using polynomial chaos theory. IEEE Transactions on Robotics, 25(1), pp. 206210.

23. Van Pham, C., \& Wang, Y. N. (2015). Robust adaptive trajectory tracking sliding mode control based on neural networks $f$ or cleaning and detecting robot 
manipulators, Journal of Intelligent \& Robotic Systems, 79(1), pp. 101-114.

24. Wang, H., Zhang, W., Tian, Y., \& Qu, Q. (2015). Sliding Mode Control for Diesel Engine Using Extended State Observer, Studies in Informatics and Control, 24(4), pp. 439-448.

25. Wai, R. J., Tu, C. Y., \& Hsieh, K. Y. (2004). Adaptive tracking control for robot manipulator, International journal of systems science, 35(11), pp. 615-627.
26. Yagiz, N., Hacioglu, Y., \& Taskin, Y. (2008). Fuzzy sliding-mode control of active suspensions, IEEE Transactions on industrial electronics, 55(11), pp. 3883-3890.

27. Yorgancioğlu, F., \& Kömürcügil, $H$. (2008). Single-input fuzzy-like moving sliding surface approach to the sliding mode control, Electrical Engineering, 90(3), pp. 199-207. 